\title{
backstory
}

\section{After the storm}

\section{Hermann M. Fritz and colleagues travelled by cargo boat through the Ayeyarwady delta in Myanmar to document the damage after cyclone Nargis.}

What was the objective of the work? On 2 May 2008, cyclone Nargis hit the Ayeyarwady delta in Myanmar, resulting in the worst natural disaster the country has seen. In the following weeks, there was a complete lack of reliable information on the impact of the storm, as neither international media nor relief organizations had direct access to the region. Three months after the event we were granted access to the area. The aim of our project was to document the extent of flooding and damage in the delta.

How did you choose fieldwork locations? The itinerary and field survey locations were pre-planned based on unofficial damage reports provided by volunteers from local non-government organizations in Myanmar, physical-storm and cyclone-track data, satellite imagery, numerical model benchmark requirements and experience gained surveying other coastal megadisasters, including the Indian Ocean tsunami and Hurricane Katrina. However, we had to modify the plan several times along the way owing to complicated logistics such as the scale of post-disaster fieldwork, limited resources and the political situation in Myanmar.

What sorts of data were you after? We were after perishable data — such as infrastructure damage before repair and reconstruction - which would otherwise be lost forever. In the flood zone we searched for water marks on buildings, scars on trees and rafted debris to determine maximum water surface elevation. We measured the distance from the nearest beach or waterway to the high water marks, to see how far the water had come in. We used exposed tree roots, land loss and eyewitness accounts to determine the degree of ephemeral coastal erosion.

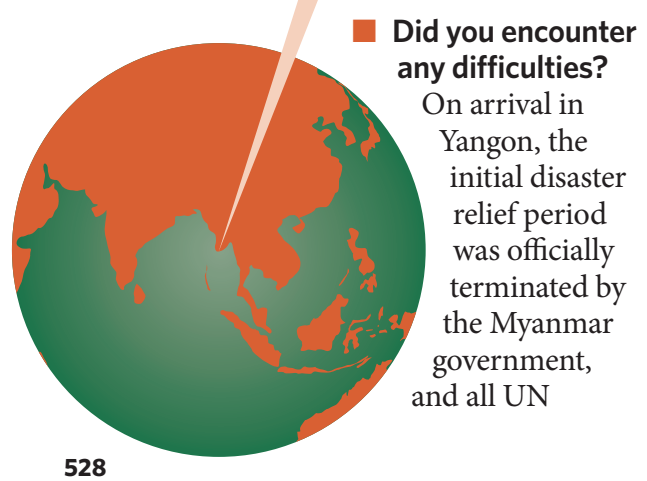

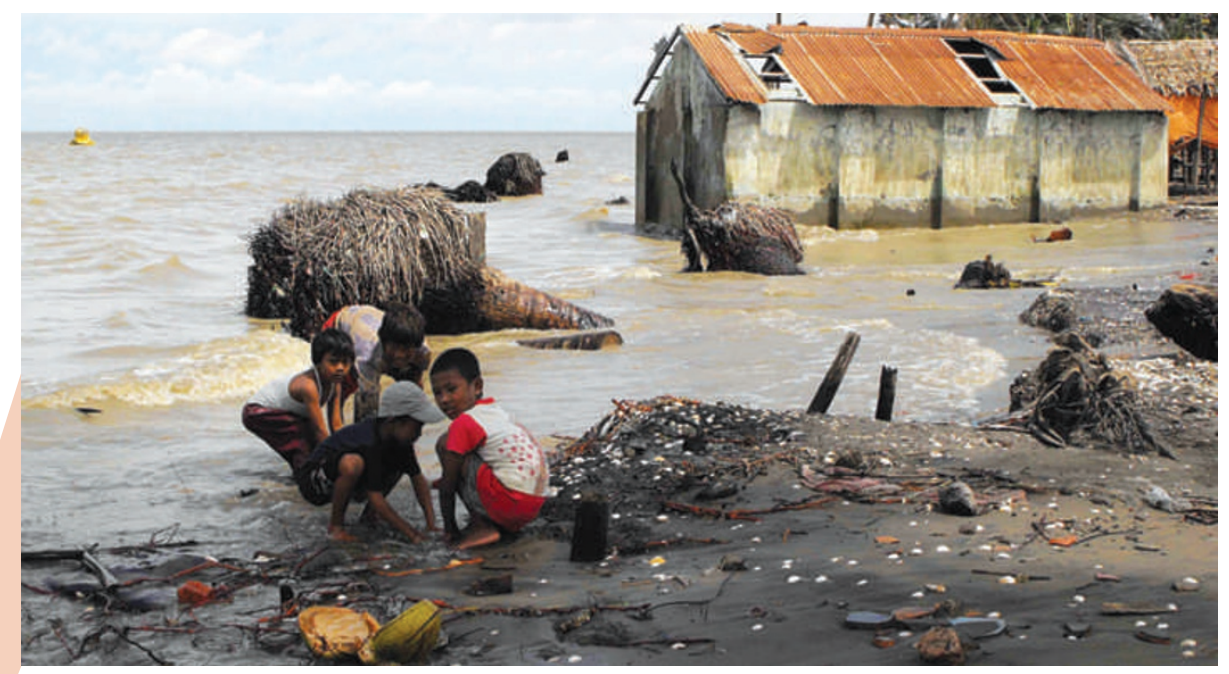

Coastal erosion and land loss at Aya near the Ayeyarwady estuary, Myanmar. At the top left you can see the golden Buddhist stupa - originally built on dry land - piercing the water surface $150 \mathrm{~m}$ offshore.

helicopters and aid flights were grounded indefinitely. We were on the passenger list of the first cancelled flight. Thus, we were forced to travel on a small cargo boat, which limited our access to rivers, waterways and coastal waters. However, although this approach was extremely slow and arduous, the old boat provided full independence between checkpoints, and flexibility in terms of which villages to survey.

\section{Did you have any encounters with dangerous animals?}

There was great concern about the dangerous snakes and saltwater crocodiles roaming in the Ayeyarwady delta. We avoided surveying several destroyed villages near an abandoned and empty crocodile farm. However, daily encounters with snakes were unavoidable - given that Myanmar has the highest rate of poisonous snakebites in the world, this was always unnerving. For example, while cruising through mangroves our local colleagues suddenly jumped back and pointed towards a massive severalmetre-long snake that had launched into the waterway and was crossing at an unbelievable speed in front of the bow - it was little comfort when it disappeared into the mangroves. One time, while interviewing a survivor next to a rice paddy, a snake attacked a nearby frog, which tried to defend itself by inflation. One of the survivors looked at the scene, commented "that's nature" and continued explaining how he survived cyclone Nargis by tying himself to the tree next to him and bouncing in the waves all night long.

\section{Any low points?}

A week of visiting one destroyed village after another and speaking to eyewitnesses who had just lost their entire families drained everyone's spirits towards the end of the survey. Drinking tea made from boiled water out of flooded rice paddies and eating pure rice meals, combined with nights in makeshift stick huts, mosquitoes and continuous monsoon rain did not aid in raising moral.

\section{What was the highlight of the trip?}

The discovery of a centuries-old golden Buddhist stupa piercing the milk coloured coastal waters offshore Aya was the highlight. For once the monsoon clouds opened and the bright sunlight appeared to put a spotlight on the scene. The stupa had originally been built on dry land, but it now marks the largest documented coastal erosion due to stormsurge flooding.

This is the Backstory to the work by Hermann M. Fritz and colleagues, published on page 448 of this issue. 